\title{
AN INTEGRATED APPROACH TO THE MANAGEMENT OF RICE ROOT KNOT NEMATODE, MELOIDOGYNE GRAMINICOLA IN SRI LANKA
}

\section{D. AMARASINGHE*}

\section{Department of Zoology, University of Kelaniya, Kelaniya, 11600, Sri Lanka}

\begin{abstract}
This study was carried out to design tools for integrated management of root knot nematode, Meloidogyne graminicola, in rice in Sri Lanka. Rice varieties namely, At5, At353, Bg304, Bg305, Bg359, Bg450, Bg94-1, Bg379-2, Ld355 and Ld356 were tested for their reactions against $M$. graminicola. Effect of poultry manure, cow-dung and paddy husk with or without cinnamon-leaf oil in reducing $M$. graminicola was studied.

It was revealed that rice varieties At5, At353, Bg304, Bg305, Bg450, Bg379-2, and Ld356 were tolerant to $M$. graminicola as compared to Bg94-1 which is highly susceptible with high rate of reproduction. Plants treated with poultry manure had significantly low nematode population. Plants grown in poultry manure enriched soil had lower yellow and dead leaves as compared to other plants. Addition of cinnamon-leaf oil improved the nematode control. This study concludes that rice varieties namely At353, Ld356, Bg304, At5, Bg305, Bg450 and Bg379-2 can be used for fields that are prone to $M$. graminicola infestation while poultry manure can be utilized at least occasionally as a nematicide cum fertilizer to reduce nematode infestation level in rice plants and to improve soil fertility.
\end{abstract}

Key words: cinnamon-leaf oil, soil amendments, rice variety, root knot nematode

\section{INTRODUCTION}

It has been estimated that around $10 \%$ of world crop production is lost as a result of plant nematodes (Nickle, 1991). In Sri Lanka, it was estimated that rice yield in severely infested fields could reach up to $72 \%$ due to root knot nematode, Meloidogyne graminicola (L. Golden and Birchfield) (Nugaliyadde et al. 2001). The infestation level of this nematode species varies from mild through moderate to severe. Due to the excessive

\footnotetext{
* Corresponding author: Email: deepika@kln.ac.lk
} 
production of eggs and easy means of spread along with water and soil, there is a high potential to expand the infected area in the country by this nematode species causing a serious loss on rice yields, particularly under sub optimal management conditions (Nugaliyadde et al., 2001).

Objectives of the present study are; to study the tolerance of some of the rice varieties recommended by the Department of Agriculture, Sri Lanka, against the infestation and population development of M. graminicola; and to determine the efficacy of the use of soil amendments and cinnamon-leaf oil on $M$. graminicola and on the growth of infested rice plants.

\section{MATERIALS AND METHODS}

Field collected M. graminicola infested rice plants were maintained in $36 \mathrm{~cm}$ diameter and $18 \mathrm{~cm}$ deep plastic basins filled with de-faunated soils to raise the nematode population. Addition of fertilizer as recommended by the Department of Agriculture, Sri Lanka and watering the plant were continued. Second stage juveniles (J2) for experimentations were collected by tease apart infested rice roots whenever necessary.

\section{Experiment I: Evaluation of rice varieties against $M$. graminicola}

Ten rice varieties (Oryza sativa) At5, At353, Bg304, Bg305, Bg359, Bg450, Bg941, Bg379-2, Ld355 and Ld356 were collected from the Plant Genetic Resources Centre at Gannoruwa, Sri Lanka.

Hundred and fifty plastic pots each measuring, $15 \mathrm{~cm}$ height $\mathrm{x} 10 \mathrm{~cm}$ diameter, were filled with $200 \mathrm{~g}$ de-faunated soil. About 30 seeds from each rice variety were soaked and allowed to germinate separately. Five day old seedlings of the test varieties were planted in these pots at the rate of one per pot. There were 15 replicates. When the plants were one week old, ten replicates of each variety were given a dose of six second stage juveniles (J2) to the base of the plants. Remaining five replicates of each variety kept free of nematodes. The pots were arranged in complete randomized design. Plants were maintained for 14 weeks. All the plants were watered daily and fertilized regularly to a calculated amount as per recommended by the Department of Agriculture. At the time of harvest the plants were carefully removed from the pots and following observations were recorded; plant height $(\mathrm{cm})$, diameter of the stem $(\mathrm{cm})$, number of total leaves, number of seeds, number of dried leaves, root length $(\mathrm{cm})$, dry weight of the root system $(\mathrm{g})$, number of root galls and total nematode population (adults, eggs, juvenile stages, J1 - J4) per plant. 


\section{Experiment II: Effects of soil amendments and cinnamon-leaf oil on rice plants infected with M. graminicola}

Cow dung, poultry manure and paddy husk to be used as soil amendments were collected from farm owners. Soil amendments were made according to the ratio of defaunated soil:soil-amendment, 2:1 v/v. Cinnamon-leaf oil was extracted by steam distillation and that contained about $86 \%$ eugenol (unpublished data).

Eighty pots measuring $15 \mathrm{~cm}$ diameter $\mathrm{x} 10 \mathrm{~cm}$ height were arranged. Ten pots each were filled with one of the following treatments; Poultry manure +Soil; Paddy husk +Soil; Cow dung + Soil; Poultry manure + Soil +0.9 ppm Cinnamon leaf oil; Paddy husk +Soil + 0.9 ppm Cinnamon-leaf oil; Cow dung + Soil + 0.9 ppm Cinnamon-leaf oil; Soil + 0.9 ppm Cinnamon-leaf oil; Soil without amendment

All the treatments were continued with regular NPK fertilization that was calculated to the rate recommended by the Department of Agriculture, Sri Lanka. Five day old rice seedlings (variety Bg351) were planted in pots at the rate of one per pot. A week after planting five active $\mathrm{J} 2$ stages of M. graminicola were introduced to the base of each plant in each pot. The experiment was arranged in Completely Randomized Design (8 treatments $x 10$ replicates). The pots were watered daily. After 14 weeks, number of green leaves, yellow leaves (chlorosis) and dead leaves were recorded. Plants were then, carefully removed and dry weight of the aerial parts of the plants and the root system, root length and the number of galls in the root system were recorded. The roots and galls in each plant were teased separately using two entomological pins in a petri dish with little amount of water to expose the nematode population. Total number of eggs, J2, J3/J4, adult females and adult males were counted separately for each plant under the low power $(10 \times 4)$ of the light microscope.

The data were analyzed statistically by means compared to the control by one way ANOVA. Mean data values were followed by \pm standard error obtained by descriptive statistics. Variables which indicated the growth of plants $i e: \%$ green leaves, stem height, plant weight and root length were log transformed and analyzed by Principal Component Analysis (PCA) to describe the variation in each pot. This multivariate analysis was used to examine the correlation structure among variables and to lessen the influence of variables that contribute relatively little information to overall patterns (Adite and Winemiller, 1997). 


\section{RESULTS AND DISCUSSION}

\section{Experiment I: Evaluation of rice varieties against M. graminicola}

Significant reduction of the plant height was observed in the variety Bg94-1 ( $\mathrm{f}=$ 9.42, $\mathrm{p}=0.037)$ and variety $\mathrm{Bg} 359(\mathrm{f}=15.54, \mathrm{p}=0.017, \mathrm{df}=14)$ when tested initially with six nematodes per plant. In addition, variety Bg 359 showed a decline of yield in presence of nematodes ( $\mathrm{f}=9.86, \mathrm{p}=0.035$ ) (Table 1 ). The mean total number of nematodes that have been developed inside galls of each variety and the initial number of nematodes are tabulated in Table 2. This shows that neither nematode infection nor population development occurred in the roots of the varieties, At353 and Bg304 (Table 2). The $\mathrm{P}_{\mathrm{f}} / \mathrm{P}_{\mathrm{i}}$ value $\left(\mathrm{P}_{\mathrm{f}}=\right.$ final population, $\mathrm{P}_{\mathrm{i}}=$ initial nematode population) shows that these plants are tolerant to $M$. graminicola. The nematodes were detected inside the roots of varieties, $\mathrm{At5}, \mathrm{Bg} 305, \mathrm{Bg} 450$ and $\mathrm{Bg} 379-2$ but $\mathrm{J} 2$ stages were remained in the roots at the same stage as they were inoculated. Their further development was not observed inside these plants. The $\mathrm{P}_{\mathrm{f}} / \mathrm{P}_{\mathrm{i}}$ value $\left(\mathrm{P}_{\mathrm{f}}=\right.$ final nematode population, $\mathrm{P}_{\mathrm{i}}=$ initial nematode population) shows that these varieties too are tolerant to $M$. graminicola. The varieties $\mathrm{Ld}$ $56, \mathrm{Bg} 94-1$ and Bg359 had varying rates of gall formation and nematode development in the galled root systems (Table 2). The highly susceptible variety was Bg94-1 which was resulted with large galls of about $3 \mathrm{~mm}$ in diameter each occupied by average of three adult females. The galled root system of the variety Bg94-1 contained about 250 mature females at the time of harvesting. The varieties Bg359 and Ld356 were rated as moderately susceptible hosts which showed varying levels of nematode development within the root system. Susceptibility of variety Bg359 was expressed through significant height reduction in presence of initial six nematodes per plant.

\section{Experiment II: Effects of soil amendments and cinnamon leaf oil on rice plants infested with M. graminicola}

The highest nematode population (mean 559.2), mean number of galls (90.8) and mean number of yellow leaves (chlorosis) (59.3) were recorded in plants without any soil amendments (Table 3 and Table 4). This was followed by paddy husk, cow dung, and poultry manure treatment respectively. Generally, the mean nematode population was positively correlated with the mean number of galls $\left(\mathrm{p}=0.000 ; \mathrm{R}^{2}=72.4 \%\right)$ and the mean number of yellow leaves/chlorosis $\left(p=0.002 ; R^{2}=62 \%\right)$. Number of yellow leaves against nematode population had a significant positive correlation $\left(\mathrm{p}=0.019 ; \mathrm{R}^{2}=69.68 \%\right)$. 
Table 1: Plant measurements $( \pm$ SE) taken 14 weeks after exposure to nematodes in different rice varieties

\begin{tabular}{|c|c|c|c|c|}
\hline Variety & $\begin{array}{l}\text { Plant height } \\
\text { SE(cm) }\end{array}$ & No. of seeds & Length of roots & Weight of roots \\
\hline At 353 & $58.3 \pm 1.04$ & $73 \pm 14.5$ & $11.11 \pm 0.95$ & $1.09 \pm 0.12$ \\
\hline control & $58.66 \pm 2.08(\mathrm{NS})$ & $90 \pm 13.6$ (NS) & $12.53 \pm 0.55(\mathrm{NS})$ & $1.08 \pm 0.11(\mathrm{NS})$ \\
\hline At 5 & $58.03 \pm 2.63$ & $107 \pm 5$ & $12.83 \pm 0.49$ & $1.57 \pm 0.40$ \\
\hline control & $58.50 \pm 2.29(\mathrm{NS})$ & $107 \pm 8(\mathrm{NS})$ & $13.16 \pm 0.85$ (NS) & $1.80 \pm 0.46(\mathrm{NS})$ \\
\hline Bg 94-1 & $47.8 \pm 3.01$ & $102 \pm 15$ & $11.96 \pm 0.058$ & $1.87 \pm 0.01$ \\
\hline \multirow[t]{2}{*}{ control } & $54.1 \pm 1.88$ & $148 \pm 21$ & $12.1 \pm 0.300(\mathrm{NS})$ & $1.86 \pm 0.04(\mathrm{NS})$ \\
\hline & $\mathrm{F}=9.42 ; \mathrm{P}=0.037$ & $F=9.86 ; P=0.035$ & & \\
\hline Bg 304 & $56.56 \pm 2.6$ & $124 \pm 5$ & $12.26 \pm 0.64$ & $1.23 \pm 0.26$ \\
\hline control & $56.86 \pm 1.09(\mathrm{NS})$ & $125 \pm 6(\mathrm{NS})$ & $12.00 \pm 0.50(\mathrm{NS})$ & $1.12 \pm 0.32(\mathrm{NS})$ \\
\hline Bg 305 & $53.43 \pm 0.49$ & $129 \pm 10$ & $12.66 \pm 1.15$ & $1.09 \pm 0.12$ \\
\hline control & $56.23 \pm 1.53(\mathrm{NS})$ & $122 \pm 21(\mathrm{NS})$ & $13.06 \pm 1.05(\mathrm{NS})$ & $1.80 \pm 0.46(\mathrm{NS})$ \\
\hline Bg 359 & $58.00 \pm 2.18$ & $149 \pm 15$ & $10.00 \pm 1.179$ & $1.62 \pm 0.72$ \\
\hline \multirow[t]{2}{*}{ control } & $65.17 \pm 2.27$ & $179 \pm 27(\mathrm{NS})$ & $10.53 \pm 0.987(\mathrm{NS})$ & $1.34 \pm 0.43(\mathrm{NS})$ \\
\hline & $\mathrm{F}=15.54 ; \mathrm{P}=0.017$ & & & \\
\hline Bg 379-2 & $52.73 \pm 6.7$ & $166 \pm 20$ & $12.36 \pm 0.8$ & $1.19 \pm 0.159$ \\
\hline control & $56.83 \pm 0.57(\mathrm{NS})$ & $162 \pm 22(\mathrm{NS})$ & $12.73 \pm 1.1(\mathrm{NS})$ & $1.17 \pm 0.08(\mathrm{NS})$ \\
\hline Bg 450 & $64.5 \pm 1.8$ & $119 \pm 3$ & $13.45 \pm 1.48$ & $1.64 \pm 0.19$ \\
\hline control & $68.5 \pm 1.3(\mathrm{NS})$ & $119 \pm 5(\mathrm{NS})$ & $13.70 \pm 1.22(\mathrm{NS})$ & $1.57 \pm 0.23(\mathrm{NS})$ \\
\hline Ld 356 & $61.46 \pm 2.6$ & $130 \pm 12$ & $13.00 \pm 1.8$ & $1.8 \pm 0.666$ \\
\hline control & $63.03 \pm 1.45(\mathrm{NS})$ & $137 \pm 20(\mathrm{NS})$ & $14.00 \pm 0.55(\mathrm{NS})$ & $1.56 \pm 0.08(\mathrm{NS})$ \\
\hline
\end{tabular}

NS - Measurements are not significantly different from that of control 
Table 2: Nematode population in test varieties infested initially with 6 juveniles of M. graminicola separately

\begin{tabular}{|c|c|c|c|}
\hline Variety & Final nematode population $\left(\mathrm{P}_{\mathrm{f}}\right.$ & $\begin{array}{l}P_{f} / P_{i} \text { value for } \\
\text { initial } 6 \text { nematodes }\end{array}$ & $\begin{array}{l}\text { Status of the variety against } \\
\text { the nematode }\end{array}$ \\
\hline At 353 & 0 & 0 & tolerant \\
\hline At 5 & 1 & 0.16 & tolerant \\
\hline Bg 94-1 & 120 & 20 & highly susceptible \\
\hline Bg 304 & 0 & 0 & tolerant \\
\hline $\mathrm{Bg} 305$ & 1 & 0.16 & tolerant \\
\hline $\mathrm{Bg} 359$ & 45 & 7.5 & moderately susceptible \\
\hline Bg 379-2 & 1 & 0.16 & tolerant \\
\hline $\mathrm{Bg} 450$ & 1 & 0.16 & tolerant \\
\hline Ld 356 & 38 & 6.3 & moderately susceptible \\
\hline
\end{tabular}

Table 3: Mean numbers of nematodes and root galls after 14 weeks of exposure to nematodes in different soil amendments $( \pm \mathrm{SE})$

\begin{tabular}{lll}
\hline Treatment & $\begin{array}{l}\text { Mean No. of } \\
\text { root galls }\end{array}$ & $\begin{array}{c}\text { Mean nematode } \\
\text { population }\end{array}$ \\
\hline Poultry manure +Soil & $14.7 \pm 3.1^{\mathrm{a}}$ & $23.3 \pm 2.2^{\mathrm{a}}$ \\
Paddy husk +Soil & $59.9 \pm 3.1^{\mathrm{c}}$ & $149.4 \pm 17.3^{\mathrm{d}}$ \\
Cow dung + Soil & $17 \pm 2.2^{\mathrm{a}}$ & $31 \pm 11.2^{\mathrm{ab}}$ \\
Poultry manure + Soil & $13.6 \pm 2.1^{\mathrm{a}}$ & $19.9 \pm 4.5^{\mathrm{a}}$ \\
$\quad+0.9$ ppm Cinnamon-leaf oil & & \\
Paddy husk +Soil & $15.7 \pm 2.3^{\mathrm{a}}$ & $58.2 \pm 12.3^{\mathrm{c}}$ \\
$\quad+0.9$ ppm Cinnamon leaf oil & & $21.4 \pm 10.1^{\mathrm{a}}$ \\
Cow dung + Soil & $14.5 \pm 2.1^{\mathrm{a}}$ & \\
$\quad+0.9$ ppm Cinnamon-leaf oil & & $143 \pm 23.2^{\mathrm{d}}$ \\
Soil + 0.9 ppm Cinnamon leaf oil & $29.3 \pm 2.3^{\mathrm{b}}$ & $559.2 \pm 24.7^{\mathrm{d}}$ \\
\hline Soil & $90.8 \pm 14.2^{\mathrm{d}}$ & \\
\hline
\end{tabular}

Data indicated by the same letters are not significantly different at $\mathrm{p}=0.05$ according to Duncan's multiple range test. 
Table 4: Plant measurements taken after 14 weeks of exposure to nematodes in different soil amendments

\begin{tabular}{|c|c|c|c|c|c|c|}
\hline Treatment & $\%$ green leaves & Mean $\%$ & Plant & Root & Plant weight & Root weigh \\
\hline & & yellow leaves & height $(\mathrm{cm})$ & length $(\mathrm{cm})$ & (g) dry & (g)dry \\
\hline Poultry manure + Soil & $80.1 \pm 7.2^{\mathrm{a}}$ & $19.9 \pm 2.3^{\mathrm{a}}$ & $36.4 \pm 4.5^{\mathrm{a}}$ & $12.2 \pm 3.2$ & $18.4 \pm 2.5$ & $12.8 \pm 1.5$ \\
\hline Paddy husk + Soil & $56.7 \pm 3.4^{\mathrm{b}}$ & $43.3 \pm 4.4^{\mathrm{bc}}$ & $30.8 \pm 4.4^{\mathrm{ab}}$ & $12.3 \pm 3.3$ & $7.8 \pm 1.4$ & $10.5 \pm 2.1$ \\
\hline Cow dung + Soil & $60.9 \pm 5.6^{\mathrm{b}}$ & $39.1 \pm 4.3^{\mathrm{b}}$ & $28.8 \pm 3.4^{\mathrm{bc}}$ & $13.8 \pm 2.1$ & $6.8 \pm 1.1$ & $8.8 \pm 2.2$ \\
\hline Poultry manure + Soil +0.9 ppm Cinnamon-leaf oil & $91.3 \pm 8.3^{\mathrm{a}}$ & $19.7 \pm 1.2^{\mathrm{a}}$ & $37.4 \pm 5.2^{\mathrm{a}}$ & $12.5 \pm 2.1$ & $17.0 \pm 2.3$ & $9.0 \pm 1.7$ \\
\hline Paddy husk + Soil +0.9 ppm Cinnamon-leaf oil & $45.4 \pm 6.5^{\mathrm{c}}$ & $54.6 \pm 4.2^{\mathrm{c}}$ & $27.7 \pm 3.3^{\mathrm{bc}}$ & $11.4 \pm 2.4$ & $6.7 \pm 1.6$ & $7.7 \pm 1.3$ \\
\hline Cow dung + Soil +0.9 ppm Cinnamon-leaf oil & $87.5 \pm 4.4^{\mathrm{a}}$ & $22.5 \pm 2.2^{\mathrm{a}}$ & $28.2 \pm 2.6^{\mathrm{bc}}$ & $13.1 \pm 2.5$ & $9.3 \pm 1.1$ & $9.3 \pm 1.2$ \\
\hline Soil + 0.9 ppm Cinnamon-leaf oil & $62.7 \pm 5.4^{\mathrm{b}}$ & $37.3 \pm 3.2^{\mathrm{bc}}$ & $29.8 \pm 2.4^{\mathrm{bc}}$ & $11.4 \pm 2.1$ & $9.2 \pm 2.0$ & $9.1 \pm 1.5$ \\
\hline Soil & $40.7 \pm 6.2^{\mathrm{c}}$ & $59.3 \pm 3.4^{\mathrm{c}}$ & $28.7 \pm 2.7^{\mathrm{bc}}$ & $11.4 \pm 1.1$ & $8.5 \pm 3.1$ & $8.7 \pm 1.6$ \\
\hline
\end{tabular}

Data in the column 2, 3 and 4 indicated by the same letters are not significantly different at $\mathrm{p}=0.05$ according to Duncan's multiple range test.

The highest values for percentage green leaves and plant height were recorded in plants treated with poultry manure combined with cinnamon-leaf oil (Table 4). This was followed by cow dung with cinnamon-leaf oil and paddy husk with cinnamon-leaf oil treatment respectively. The lowest values were recorded in treatments without any soil amendment.

According to the principal components analysis the data was described to a proportion of $98 \%$ in principal component 1 axes (PC1- soil amendment) and 1\% in the PC2 (plant height). Percentage green leaves scored the highest negative value on soil amendment. Dead leaves and treatments without soil amendments were aggregated at the extreme where the treatments with lowest percentage of green leaves. One way ANOVA for soil amendment (PC1 scores) recorded the $\mathrm{p}$ value $0.0000, \mathrm{~F}$ value 3647.51. The regression analysis done for nematode population against soil amendment (PC1 score) indicated a significant correlation $\left(\mathrm{p}=0.000, \mathrm{R}^{2}=87.6 \%\right)$. This study envisages that the plants with highest growth consists the lowest nematode population in their root systems. Balanced ANOVA carried out for the nematode population indicated that; the nematode population vary significantly when the type of soil amendment varies $(p=0.000 \mathrm{~F}=$ 2703.4); the nematode population vary significantly when cinnamon-leaf oil is added $(\mathrm{p}=0.000, \mathrm{~F}=17.20)$; the nematode population vary significantly when the type of soil amendment and cinnamon-leaf oil application varies $(\mathrm{p}=0.000, \mathrm{~F}=420.42)$. 
Generally this study shows that the nutrients available in the soil amendments, promoted the growth of plants and the soil amendments by any means have significantly inhibited the nematode population. Out of the three types of soil amendments used in this study, poultry manure had result the significant higher plant growth and significant lower nematode population and generally a higher plant height and lower chlorosis than all the other amendments. Thus, it is evident that poultry manure has enhanced the plant growth. Similar results have been obtained using same treatments tested against $M$. graminicola in another experiment (Amarasinghe et al., 2007). The present study confirms the results obtained previously.

The addition of organic materials to soil has been used in managing plant parasitic nematodes and has resulted in increased crop yield. Utilization of waste materials such as oilseed cakes, chitin, compost, livestock and poultry manures, and cellulose wastes appears promising for reducing populations of plant parasitic nematodes (Akhtar \& Mahmood, 1996). Siddiqui and Mashkoor Alam (1990) reported that the combined effect of sawdust and ammonium sulphate was greater than for either of the separate treatments both with respect to nematode control and to the improvement in plant growth. The use of composted dry cork, dry grape marc (fruit residue after pressing) and a 1:1 mixture of dry olive marc combined with dry rice husk as an amendment to potting mixtures has been found reducing root galling and final population of Meloidogyne javanica and M. incognita (Nico, et al., 2004). Such increase in plant growth and reduction in root galling have been attributed to either improvement in soil condition resulting in greater root growth, thereby enhancing the utilization of soil nutrients and to changes in the biotic and abiotic environment of plants respectively. These ultimately alter the host parasite relationship thereby minimizing the nematode damage.

\section{CONCLUSIONS}

The rice varieties At5, At353, Bg304, Bg305, Bg450, Bg379-2, and Ld355 are tolerant to $M$. graminicola. The varieties Bg94-1, Bg359 and Ld356 were found susceptible to $M$. graminicola of which Bg94-1 was highly susceptible with high rate of reproduction while $\mathrm{Bg} 359$ and $\mathrm{Ld} 356$ were moderately susceptible with low rate of reproduction of the nematode. The poultry manure significantly reduced the nematode population. Combined application of cinnamon-leaf oil and soil amendment had a better effect compared to application of soil amendment alone in reducing the nematode population. 


\section{ACKNOWLEDGEMENT}

Author acknowledges the financial support by Research Grant RP/03/02/07/01/2006 of University of Kelaniya, Sri Lanka.

\section{REFERENCES}

Akhtar M. \& I. Mahmood. 1996. Organic soil amendments in relation to nematode management with particular reference to India. Integrated Pest Management Reviews 1: 201-215.

Adite A.K.O. \& Winemiller. 1997. Trophic Ecology and Eco-morphology of Fish Assemblages in Coastal Lakes of Benin, West Africa. Ecoscience 4(1): 182-195. Department of Wildlife and Fisheries Sciences, Texas A \& M University, College Station, Texas.

Amarasinghe L.D., K.A.D.P.S. Kariyapperuma and H.N.I. Pathirana. 2007. Study on approaches to integrated control of Meloidogyne graminicola in rice. Journal of Science of the University of Kelaniya 3: 29-46.

Nico A.I., R.M. Rafael, M. Jimenez-Diaz \& P. Castillo. 2004. Control of root knot nematodes by composted agro industrial wastes in potting mixtures. Crop Protection 23 (7): 581-587.

Nugaliyadde L., D.M.N. Dissanayake, H.U.D.N. Herath, C.M.D. Dharmasena, D.M. Jayasundera \& H.M.R.K. Ekanayake. 2001. Outbreak of rice root knot nematode, Meloidogyne graminicola in Nikewaratiya, Kurunegala in Maha 2000/2001. Annals of the Sri Lanka Department of Agriculture 3: 373-374p.

Siddiqui M.A. \& M. Mashkoor Alam. 1990. Sawdust as soil amendments for control of nematodes infesting some vegetables. Biological Wastes 33 (2): 123-129. 